\title{
Is commissural closure associated with mitral annuloplasty a durable technique for the treatment of mitral regurgitation? A long-term ( $\leq 15$ years) clinical and echocardiographic study
}

\author{
Michele De Bonis, MD, Elisabetta Lapenna, MD, Maurizio Taramasso, MD, Alberto Pozzoli, MD, \\ Giovanni La Canna, MD, Maria Chiara Calabrese, MD, and Ottavio Alfieri, MD
}

\begin{abstract}
Objective: Mitral regurgitation (MR) due to commissural prolapse/flail can be corrected by suturing the margins of the anterior and posterior leaflets in the commissural area (commissural closure). The long-term results of this type of repair are unknown. Our aim was to assess the clinical and echocardiographic outcomes of this technique up to 15 years after surgery.
\end{abstract}

\begin{abstract}
Methods: From 1997 to 2007, 125 patients (age, $56.8 \pm 15.7$ years; left ventricular ejection fraction, $58.1 \% \pm$ $7.1 \%$ ) with MR due to pure commissural prolapse/flail of 1 or both leaflets underwent commissural closure combined with annuloplasty. The etiology of the disease was degenerative in $88.8 \%$ and endocarditis in $11.2 \%$. The commissural region involved was posteromedial in 96 patients $(76.8 \%)$ and anterolateral in $29(23.2 \%)$.
\end{abstract}

\begin{abstract}
Results: Hospital mortality was $1.6 \%$. At discharge, MR was absent or mild in 120 patients $(97.5 \%)$ and moderate $(2+/ 4+)$ in $3(2.4 \%)$. Clinical and echocardiographic follow-up was $98.4 \%$ complete (mean length, $7.1 \pm$ 3.0 years; median, 6.7 ; longest follow-up, 15). At 11 years, the actuarial survival, freedom from cardiac death, and freedom from reoperation was $78.8 \% \pm 6.2 \%, 95.2 \% \pm 3.3 \%$, and $97.4 \% \pm 1.4 \%$, respectively. At the last echocardiographic examination, MR $3+$ or greater was demonstrated in 4 patients $(3.3 \%)$. Freedom from MR $3+$ or greater at 11 years was $96.3 \% \pm 1.7 \%$. No predictors for recurrence of MR $3+$ or greater were identified. The mean mitral valve area and gradient was $2.9 \pm 0.4 \mathrm{~cm}^{2}$ and $3.4 \pm 1.1 \mathrm{~mm} \mathrm{Hg}$, respectively. New York Heart Association class I to II was documented in all cases.
\end{abstract}

Conclusions: Commissural closure repair combined with annuloplasty provides excellent clinical and echocardiographic long-term results in patients with MR due to commissural lesions. (J Thorac Cardiovasc Surg 2014;147:1900-6)

Degenerative mitral valve (MV) regurgitation can now be successfully repaired in expert centers in about $95 \%$ of patients using a large array of contemporary surgical techniques. ${ }^{1-3}$ Some mitral lesions, such as prolapse of the central scallop of the posterior leaflet (P2), are routinely treated in a standardized fashion, with excellent very long-term results. ${ }^{4}$ However, in presence of other mechanisms of mitral regurgitation (MR), such as commissural chordal rupture or elongation, several different surgical methods have been suggested. ${ }^{5-11}$ The absence of a unique and standardized approach in this context demonstrates the challenging feature of "commissural MR." A commissural regurgitant jet can result from the pathologic involvement of the anterior or posterior, or

From the Cardiac Surgery Department, San Raffaele Scientific Institute, Milan, Italy Disclosures: Authors have nothing to disclose with regard to commercial support. Received for publication April 24, 2013; revisions received June 18, 2013; accepted for publication July 9, 2013; available ahead of print Aug 28, 2013.

Address for reprints: Michele De Bonis, MD, Cardiac Surgery Department, San Raffaele Scientific Institute, Via Olgettina 60, Milan 20132, Italy (E-mail: debonis.michele@hsr.it).

0022-5223/\$36.00

Copyright (c) 2014 by The American Association for Thoracic Surgery http://dx.doi.org/10.1016/j.jtcvs.2013.07.009 both, leaflets, and a technical solution tailored to the specific mechanism is usually required. In addition, the frailty of the valve tissue at this level further increases the complexity of the repair. In our institution, commissural lesions are preferentially treated with a "functional," rather than an "anatomic," repair using edge-to-edge approximation of the anterior and posterior leaflet at the commissural area (commissural closure). We have previously reported the mid-term results of this technique, which were very satisfactory in terms of the effectiveness and durability. ${ }^{12}$ We describe the long-term $(\leq 15$ years $)$ clinical and echocardiographic outcomes of this technique in patients with degenerative or postendocarditis prolapse or flail of the commissural mitral region.

\section{METHODS}

\section{Patients}

From 1997 to 2007, 125 consecutive patients underwent edge-to-edge "commissural closure" repair at our institution for severe MR due to pure commissural prolapse or flail of 1 or both leaflets. Patients who concomitantly underwent other reconstructive procedures in addition to commissural repair for other mitral lesions were not included. The preoperative, intraoperative, and postoperative data were retrospectively reviewed from the hospital database and patient records. All patients provided written informed consent for the operation and for the anonymous 


\section{Abbreviations and Acronyms \\ MR = mitral regurgitation \\ MV = mitral valve \\ NYHA $=$ New York Heart Association}

study of their data. The ethical committee of San Raffaele Scientific Institute approved the study. The preoperative clinical characteristics and operative data are listed in Table 1. The mean age was $56.8 \pm 15.7$ years, and most of the patients were in New York Heart Association (NYHA) functional class I or II ( 93 of $125,74.4 \%$ ). About $20 \%$ of them were in atrial fibrillation. The mean left ventricular ejection fraction was $58.1 \% \pm$ $7.19 \%$, with significant left ventricular dysfunction (ejection fraction $<45 \%)$ in 6 patients only $(4.8 \%)$. The etiology of MR was degenerative in 111 patients $(88.8 \%)$ and endocarditis in $14(11.2 \%)$. Previous cardiac surgery had been performed in 3 patients: tricuspid valve repair and ascending aorta replacement in 1, aortic valve replacement in 1, and closure of an atrial septum defect in 1 patient.

\section{Echocardiographic Study}

All patients underwent preoperative transthoracic echocardiography followed by transesophageal Doppler echocardiography. According to Carpentier's classification, ${ }^{13}$ the mechanism of MR was a type 2 lesion in all patients. In most cases, the posterior leaflet or both leaflets were involved by the prolapse or flail in the commissural area. In less than $20 \%$ of the patients, only the anterior leaflet was prolapsing (Table 1). Typically, a commissural lesion was responsible for a complex or eccentric jet of MR originating from the posteromedial $(96,76.8 \%)$ or anterolateral $(29$, $23.2 \%$ ) commissure. Doppler color flow imaging was used to semiquantitatively quantify the degree of MR, which was defined as mild $(1+/ 4+)$ if the percentage of the left atrial area subtended by the MR jet was $1 \%$ to $15 \%$, moderate $(2+/ 4+)$ if it was $16 \%$ to $35 \%$, moderate-to-severe $(3+/$ $4+)$ if $36 \%$ to $55 \%$, and severe (4+/4+) if greater than $55 \% .{ }^{14}$ In addition, the vena contracta width at the narrowest portion of the regurgitant jet was measured as follows: $0.3 \mathrm{~cm}$ or less, 1 to $2+; 0.3$ to $0.5 \mathrm{~cm}, 3+$; and $0.5 \mathrm{~cm}$ or more, $4+.{ }^{15}$ Transesophageal echocardiography was repeated intraoperatively after the induction of general anesthesia and immediately after weaning from cardiopulmonary bypass once the hemodynamic conditions had stabilized. A transthoracic echocardiographic examination was then performed at hospital discharge and at follow-up.

\section{Operative Technique}

The surgical method used to correct commissural prolapse or flail has been previously reported. ${ }^{12}$ The operation was performed through a median sternotomy in 120 patients and through a right anterior minithoracotomy in 5. The MV was approached through a conventional left atrial incision and systematically assessed to identify the location and extension of the commissural prolapse or flail. Typically, elongated or ruptured chordae of the anterior and/or posterior leaflet at the commissure were found. The normal chordae on 1 or both leaflets adjacent to the area of prolapse were identified to mark the limits of the commissural closure. We used the following definition of mitral commissures: "the junctions of the leaflets at their mural attachments." 16 The remaining prolapsing commissural region was then closed by suturing the free edge of the anterior leaflet to the free edge of the posterior leaflet with a 4.0 or 5.0 polypropylene buttress suture followed by a continuous running suture. According to the location of the regurgitant jet and the site of prolapse identified intraoperatively, the edge-to-edge suture was performed at the posteromedial commissure in 96 patients $(76.8 \%)$ and the anterolateral in the remaining $29(23.2 \%)$.

Annuloplasty was added to complete the repair in all cases, with the exception of 2 patients, in whom the annulus was either considered normal
TABLE 1. Baseline characteristics of the patients and operative data

\begin{tabular}{|c|c|}
\hline Characteristic & Value \\
\hline Patients (n) & 125 \\
\hline \multicolumn{2}{|l|}{ Age (y) } \\
\hline Mean \pm SD & $56.8 \pm 15.7$ \\
\hline Range & $18-84$ \\
\hline Male gender (n) & $86(68.8)$ \\
\hline \multicolumn{2}{|l|}{ NYHA class (n) } \\
\hline I & $38(30.4)$ \\
\hline II & $55(44)$ \\
\hline III & $27(21.6)$ \\
\hline IV & $5(4)$ \\
\hline $\mathrm{AF}$ at presentation (n) & $26(20.8)$ \\
\hline \multicolumn{2}{|l|}{ Etiology of MR (n) } \\
\hline Degenerative & $111(88.8)$ \\
\hline Healed infective endocarditis & $14(11.2)$ \\
\hline \multicolumn{2}{|l|}{ Commissure involved (n) } \\
\hline Posteromedial & $96(76.8)$ \\
\hline Anterolateral & $29(23.2)$ \\
\hline \multicolumn{2}{|l|}{ Leaflets involved (n) } \\
\hline Posterior leaflet & $48(38.4)$ \\
\hline Anterior leaflet & $24(19.2)$ \\
\hline Both leaflets & $53(42.4)$ \\
\hline Previous cardiac operation (n) & $3(2.4)$ \\
\hline \multicolumn{2}{|l|}{$\operatorname{LVEF}(\%)$} \\
\hline Mean \pm SD & $58.1 \pm 7.19$ \\
\hline Range & $30-72$ \\
\hline \multicolumn{2}{|l|}{ LVEDD (mm) } \\
\hline Mean \pm SD & $58.4 \pm 6.14$ \\
\hline Range & $45-73$ \\
\hline \multicolumn{2}{|l|}{ LVESD (mm) } \\
\hline Mean \pm SD & $37.3 \pm 5.68$ \\
\hline Range & $30-58$ \\
\hline \multicolumn{2}{|l|}{ SPAP (mm Hg) } \\
\hline Mean $\pm \mathrm{SD}$ & $42.7 \pm 14.33$ \\
\hline Range & $20-70$ \\
\hline \multicolumn{2}{|l|}{ Type of mitral annuloplasty (n) } \\
\hline Autologous pericardium & $8(6.5)$ \\
\hline Seguin St Jude Medical & $75(60.9)$ \\
\hline Carpentier-Edwards classic & $3(2.4)$ \\
\hline Tailor St Jude Medical & $37(30)$ \\
\hline \multicolumn{2}{|l|}{ Annuloplasty ring size } \\
\hline Mean \pm SD & $34 \pm 3$ \\
\hline Range & $27-40$ \\
\hline \multicolumn{2}{|l|}{ Associated procedures (n) } \\
\hline AVR & $5(4)$ \\
\hline PFO closure & $13(10.4)$ \\
\hline CABG & $16(12.8)$ \\
\hline Tricuspid annuloplasty & $29(23.2)$ \\
\hline Radiofrequency ablation of $\mathrm{AF}$ & $16(12.8)$ \\
\hline Ascending aorta replacement/reduction & $4(3.2)$ \\
\hline David operation & $1(0.8)$ \\
\hline
\end{tabular}

Data presented as n (\%), unless otherwise noted. $S D$, Standard deviation; $N Y H A$, New York Heart Association; $A F$, atrial fibrillation; $M R$, mitral regurgitation; $L V E F$, left ventricular ejection fraction; $L V E D D$, left ventricular end-diastolic diameter; $L V E S D$, left ventricular end-systolic diameter; $S P A P$, systolic pulmonary artery pressure; $A V R$, aortic valve replacement; $P F O$, patent foramen ovale; $C A B G$, coronary artery bypass grafting. 
in size or severely calcified. A semirigid or flexible prosthetic ring was implanted in 115 patients, and a posterior annuloplasty with autologous pericardium was preferred in 8 endocarditis cases. The mean ring size was $34 \pm$ $3 \mathrm{~mm}$. The final valve area was occasionally measured using Hegar dilators to exclude mitral stenosis. The competence of the valve was checked by forceful saline injection into the left ventricle. In 65 patients (52\%), other cardiac procedures were performed in association (Table 1). The vast majority were tricuspid annuloplasty, radiofrequency ablation of atrial fibrillation, and myocardial revascularization. Excluding patients undergoing associated cardiac procedures, the mean cardiopulmonary bypass and ischemic time was $61 \pm 14.7$ and $47 \pm 12.2$ minutes, respectively. After weaning from cardiopulmonary bypass, transesophageal echocardiography was routinely performed to assess the final results of the repair and measure the MV area. A global MV area of $2.5 \mathrm{~cm}^{2}$ was considered satisfactory for normal size patients.

\section{Follow-Up}

Follow-up data for the hospital survivors were collected retrospectively by reviewing the outpatient clinic charts and transthoracic echocardiographic examinations performed in our institution or by telephone interview with the patient and referring cardiologist. Clinical and echocardiographic follow-up information was available for 121 of the 123 hospital survivors (98.4\% complete). Two patients were lost to follow-up. The mean length of clinical follow-up was $7.1 \pm 3.0$ years (range, 6 months to 15 years), with a median of 6.7 years (interquartile range, 5.3-8.4). The last echocardiographic examination was performed a mean of $6.6 \pm 3.0$ years after surgery (median, 6.3; interquartile range, 4.8-8.1).

\section{Statistical Analysis}

Calculations were performed using the Statistical Package for Social Sciences, version 11.5 (SPSS Inc, Chicago, Ill) for Windows (Microsoft Corp, Redmond, Wash), software package.

Data are expressed as the mean \pm standard deviation or median and interquartile range. For continuous normally distributed data, comparisons between 2 groups were performed with Student $t$ test for unpaired samples, as indicated. If the continuous data were not normally distributed, the Mann-Whitney $U$ test or Wilcoxon signed rank test was used for independent or related samples, respectively. A comparison of the categorical variables was performed using the chi-square test and Fisher's exact test. The NYHA functional class and MR grade were treated as ordinal variables and compared using the Wilcoxon signed rank test (related samples) or the Mann-Whitney $U$ test (independent samples). Survival and freedom from events were evaluated using Kaplan-Meier analysis. For actuarial estimates, the data are presented as the mean \pm the standard error. Comparisons among groups were performed using the log-rank method. Univariate analysis of the predictors of recurrence of MR grade $3+$ or more was performed using Cox proportional hazards regression analysis.

\section{RESULTS \\ Early Results}

Two patients died in hospital (1.6\%). One patient developed low cardiac output syndrome and the other patient, an 84-year-old man who had undergone mitral repair and coronary artery bypass grafting, died of postoperative acute aortic dissection. In the remaining patients, the postoperative course was rather smooth. A few complications occurred (Table 2). At hospital discharge, all hospital survivors underwent transthoracic echocardiography. MR was absent or mild in 120 patients $(97.5 \%)$ and moderate $(2+/$ $4+)$ in $3(2.4 \%)$. Systolic anterior motion of the anterior leaflet was never detected.
TABLE 2. Postoperative and late complications

\begin{tabular}{lc}
\hline \multicolumn{1}{c}{ Variable } & $\mathbf{n}(\%)$ \\
\hline Postoperative morbidity (total patients, 125$)$ & \\
Low output syndrome & $2(1.6)$ \\
Pericardial effusion & $2(1.6)$ \\
Prolonged ventilatory support $(>48 \mathrm{~h})$ & $1(0.8)$ \\
Re-exploration for bleeding & $1(0.8)$ \\
Pacemaker implantation & $1(0.8)$ \\
Aortic dissection & $1(0.8)$ \\
Late complications (total patients, 121$)$ & \\
Stroke & $3(2.4)$ \\
AMI & $2(1.6)$ \\
Congestive heart failure & $2(1.6)$ \\
TIA & $1(0.8)$ \\
\hline AMI, Acute myocardial infarction; TIA, transient ischemic attack.
\end{tabular}

\section{Late Results}

Sixteen late deaths occurred, but only one was cardiac related (acute myocardial infarction and cardiac arrest 8.4 years after repair). The remaining 15 patients had a mean age of $76 \pm 8.6$ years (range, 66-87) at death, and most of them died of cancer ( 9 patients). The other causes of death were stroke in 3 patients, gastrointestinal bleeding in 1 patient, rupture of the descending thoracic aorta aneurysm in 1 patient, and car accident in 1 patient. The gastrointestinal bleeding and stroke episodes occurred several years after the mitral repair procedures in patients who were in regular sinus rhythm and who had been taking warfarin only for the first 3 postoperative months. Therefore, none of those late events seemed to be cardiac related. The overall actuarial survival at 11 years was $78.8 \% \pm 6.2 \%$ (Figure 1), and the freedom from cardiac death was $95.2 \% \pm 3.3 \%$ (Figure 2). Three patients underwent repeat surgery for significant recurrent MR at 8 months, 9 months, and 2.1 years after the initial repair. The cause of failure was endocarditis in 1 patient and leaflet retraction due to valve fibrocalcification in 1 patient. In the third patient, the cause of recurrent MR remained unclear. The intraoperative findings were also unclear, because the reoperation was performed at another institution. Two patients underwent MV replacement with a mechanical prosthesis, and in 1 patient, repeat repair was possible. The freedom from reoperation at 11 years was $97.4 \% \pm 1.4 \%$ (Figure 3). At least 1 transthoracic echocardiographic scan was available at follow-up for 121 patients (Table 3). At the last echocardiogram, the mean mitral valve area and gradient was $2.9 \pm 0.4 \mathrm{~cm}^{2}$ and 3.4 $\pm 1.1 \mathrm{~mm} \mathrm{Hg}$ (median, 3), respectively. MR was absent or mild in 108 of the 121 patients $(89.3 \%)$, moderate in 9 $(7.4 \%)$, moderate-to-severe in $1(0.8 \%)$, and severe in 3 $(2.5 \%)$. Of 4 patients $(3.3 \%)$ with MR grade $3+$ or greater, 3 underwent repeat surgery and 1 was still in follow-up. The freedom from MR grade 3+ or greater at 11 years was $96.3 \% \pm 1.7 \%$ (Figure 4). Preoperative factors such as age, gender, left ventricular function, cardiac rhythm, and 


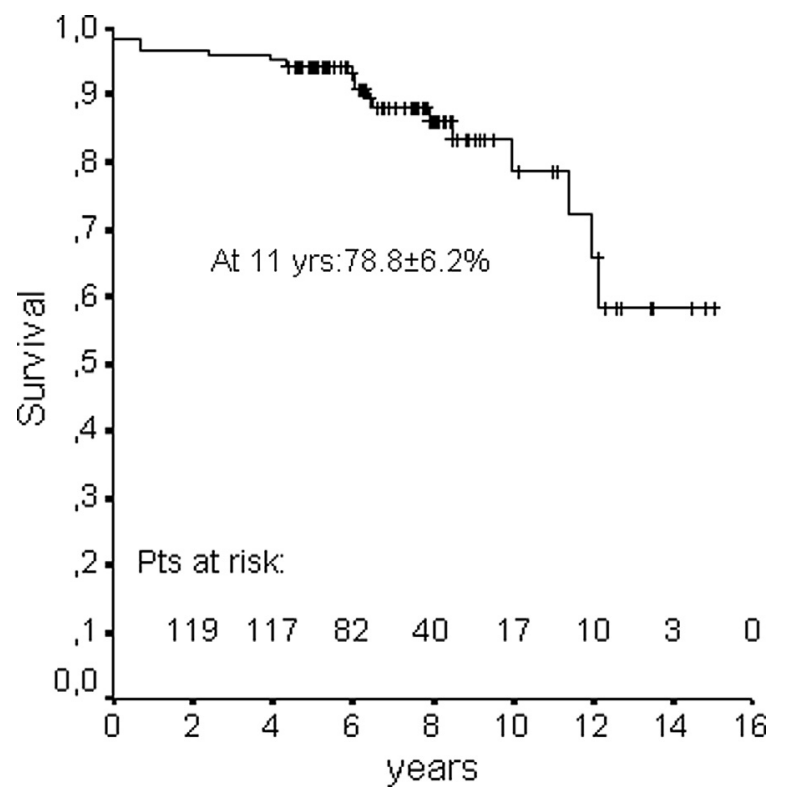

FIGURE 1. Actuarial overall survival.

symptom severity were not identified as predictors of MR recurrence. Similarly, the etiology of MR, involvement of the anterior or posterior, or both, leaflets in the mechanism of MR, and the location of the regurgitant jet had no influence on the failure of the repair. More complex patients requiring cardiac operations in addition to MV repair did not have a greater rate of recurrent MR grade $3+$ or greater or MR grade 2 or greater compared with those who underwent MV reconstruction only (Table 4). Significant clinical improvement was also documented, because all patients

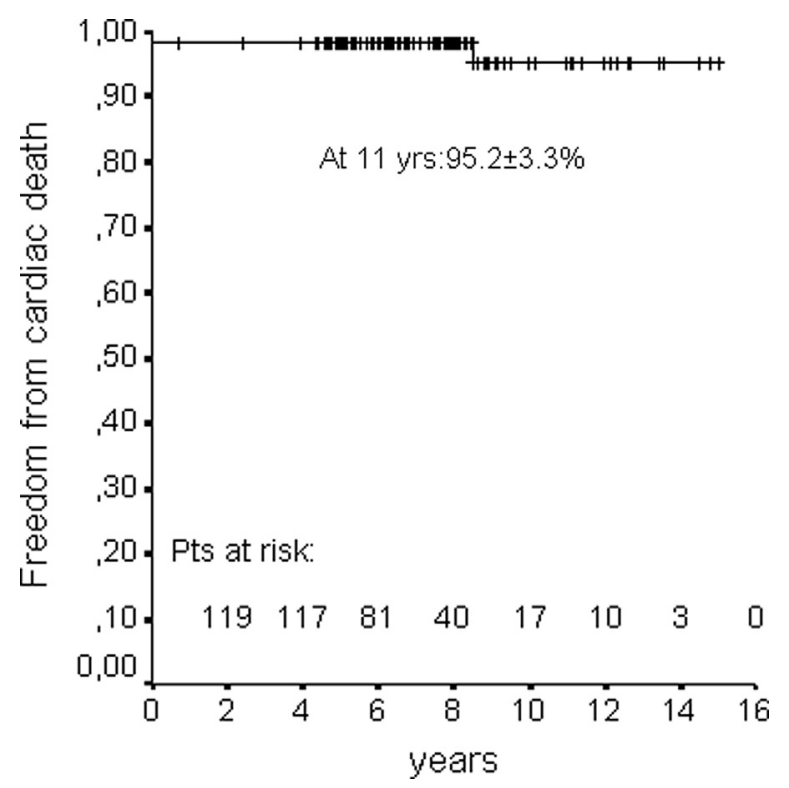

FIGURE 2. Actuarial freedom from cardiac death.

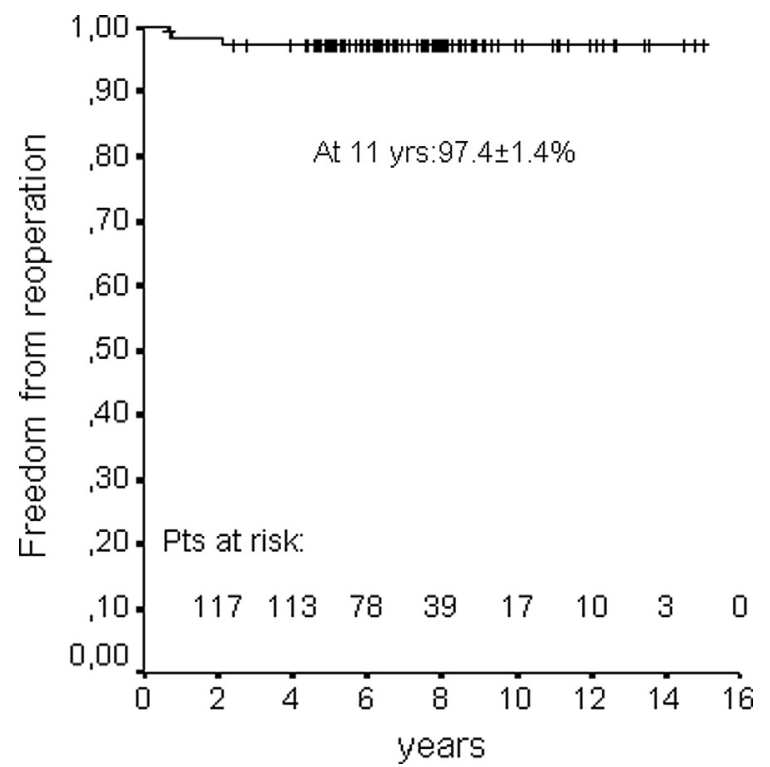

FIGURE 3. Actuarial freedom from reoperation.

were in NYHA functional class I or II compared with about one fourth $(25.6 \%)$ who had been in NYHA class III or IV before surgery $(P<.0001)$.

\section{DISCUSSION}

The main finding of the present study was that commissural closure combined with annuloplasty provides excellent clinical and echocardiographic long-term results in patients with severe degenerative or postendocarditis MR due to commissural lesions. To the best of our knowledge, this is the first series reporting the late results of this approach in the setting of isolated commissural MV regurgitation. Previous studies focusing on the surgical treatment of commissural MR enrolled patients whose

TABLE 3. Echocardiographic data at follow-up

\begin{tabular}{lc}
\hline \multicolumn{1}{c}{ Variable } & Value \\
\hline MR & \\
$\quad$ Absent or mild & $108(89.3)$ \\
$\quad$ Moderate & $9(7.4)$ \\
$\quad$ Moderate to severe & $1(0.8)$ \\
$\quad$ Severe & $3(2.5)$ \\
LVEF (\%) & $57 \pm 8.5$ \\
LVEDD (mm) & $52.3 \pm 4.32$ \\
LVESD (mm) & $34.8 \pm 4.4$ \\
SPAP (mm Hg) & $28 \pm 5.3$ \\
Mitral valve area (cm $\left.{ }^{2}\right)$ & $2.9 \pm 0.4$ \\
Mitral gradient (mm Hg) & $3.4 \pm 1.1$ \\
\hline Data presented as n (\%) or mean \pm standard deviation. $M R$, Mitral regurgitation; \\
LVEF, left ventricular ejection fraction; $L V E D D$, left ventricular end-diastolic diam- \\
eter; $L V E S D$, left ventricular end-systolic diameter; SPAP, systolic pulmonary artery \\
pressure.
\end{tabular}




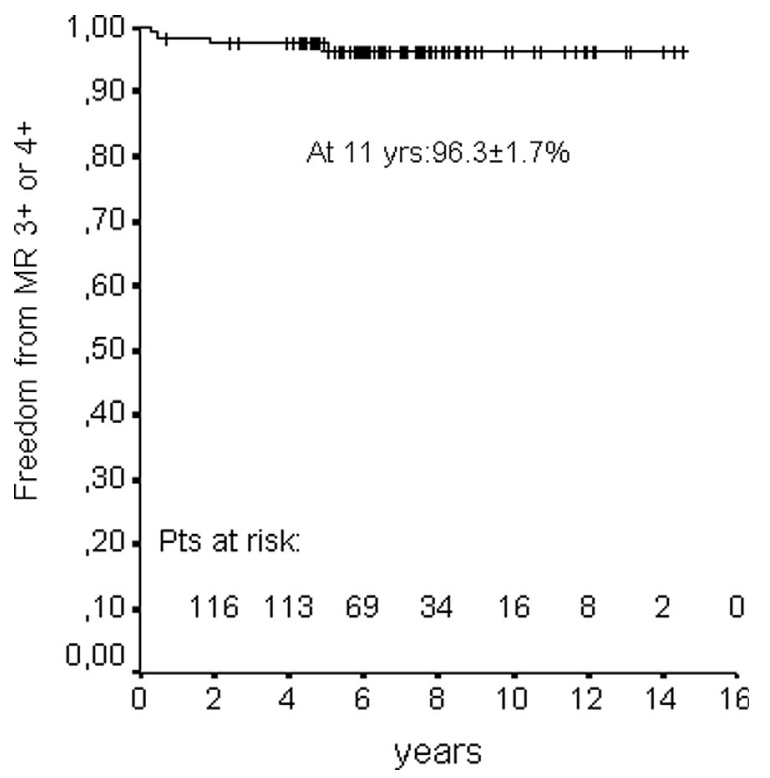

FIGURE 4. Actuarial freedom from mitral regurgitation grade $3+$ or greater. $M R$, Mitral regurgitation.

commissural mitral pathology was often associated with other mitral lesions requiring specific concomitant treatment. ${ }^{6-11,17-22}$ In addition, no long-term outcome data were provided. However, in the present study, we specifically included only patients with isolated commissural prolapse who were treated exclusively with an edge-toedge approximation of the commissural part of the 2 leaflets. Very satisfactory early and mid-term results were previously reported by our group for patients treated with this approach. ${ }^{12}$ In the present study, we focused on the late outcomes of this procedure.

From a clinical viewpoint, the freedom from cardiac death at 11 years was excellent. A cardiac-related death occurred in only 1 patient, and the late mortality was not

TABLE 4. Predictors of recurrence of MR grade $3+$ or greater

\begin{tabular}{lllc}
\hline \multicolumn{1}{c}{ Variable } & HR & $\mathbf{9 5} \%$ CI & $\boldsymbol{P}$ value \\
\hline Age & 0.1 & $0.9-1.0$ & .5 \\
Male sex & 2.1 & $0.3-15.5$ & .4 \\
LVEF & 0.9 & $0.8-1.1$ & .8 \\
NYHA class > & 1.0 & $0.1-10.2$ & .9 \\
AF & 4.0 & $0.5-28.4$ & .1 \\
Endocarditis etiology & 0.04 & $0-2.1$ & .6 \\
Anterior leaflet prolapse & 4.4 & $0.6-31.4$ & .1 \\
Bileaflet prolapse & 0.4 & $0.04-4.2$ & .4 \\
Posterior leaflet prolapse & 0.5 & $0.05-5.1$ & .5 \\
Posterior vs anterior & 0.2 & $0.03-1.9$ & .1 \\
$\quad$ commissural lesion & & & \\
Associated procedures & 3.3 & $0.3-32.3$ & .2 \\
\hline
\end{tabular}

$M R$, Mitral regurgitation; $H R$, hazard ratio; $C I$, confidence interval; $L V E F$, left ventricular ejection fraction; NYHA, New York Heart Association; $A F$, atrial fibrillation. valve related for any patient. The overall survival was somehow lower than expected; however, this was mainly because of the relatively high number of elderly patients who died of noncardiac reasons (ie, cancer). About one fourth of the patients were in NYHA class III or IV before surgery, but at follow-up, all patients were in functional NYHA class I or II, confirming the positive clinical effect of the repair procedure.

Compared with the results obtained at mid-term, ${ }^{12}$ a few more repair failures were documented, as expected, with the increasing follow-up duration. Nevertheless, the overall incidence of repeat operations and recurrence of significant MR remained extremely low. One strength of the present study was that almost all the hospital survivors $(98.3 \%)$ had an echocardiogram available at the last follow-up visit. Recurrence of MR grade 3+ or greater was demonstrated in only 4 patients $(3.3 \%)$, for excellent freedom from reoperation and freedom from echocardiographically determined significant MR. Similar to what has been reported by other groups, ${ }^{19}$ we did not find mitral stenosis, suture dehiscence, or recurrent prolapse at the site of repair in any of our patients. One patient had recurrence of severe MR about 9 months after repair owing to fibrocalcific retraction of the mitral leaflets. Whether this fibrotic degeneration of the mitral valve within such a short period could have been related to the commissural closure remains unclear. Considering that this phenomenon was not documented in any other patient of this or other similar series, ${ }^{19}$ this possibility seems rather unlikely.

The long-term results we have reported were certainly very satisfactory, considering that commissural prolapse is commonly believed to be a difficult lesion to treat. ${ }^{6} \mathrm{~A}$ commissural regurgitant jet can be due to lesions involving the anterior or posterior, or both, leaflets, and the frailty of the valve tissue at this level further increases the complexity of the repair. Several different surgical methods have been suggested to treat this disorder, including neochordae implantation, ${ }^{5}$ chordal transposition, ${ }^{7}$ extended leaflet sliding technique, ${ }^{8}$ papillary muscle repositioning, ${ }^{9}$ and replacement of the commissural area by a partial mitral homograft $^{10}$ or the posterior leaflet of the tricuspid valve. ${ }^{11}$ Those surgical procedures can be challenging for a number of reasons. For instance, judgment of the artificial chordal length can be difficult owing to the fan-shaped anatomy of the commissural chordae. ${ }^{5}$ Also, chordal reimplantation or transposition is not easy because of the fragility of the commissural chordae. ${ }^{23}$ Leaflet resection combined with extended sliding carries the risk of distortion of the subvalvular apparatus. ${ }^{8}$ Finally, papillary muscle repositioning requires manipulation of the subvalvular apparatus, and many surgeons have little confidence with it. Unlike those methods, suture closure of the commissure followed by annuloplasty eliminates the prolapse simply and rapidly and is a single, standardized, and easily reproducible approach 
that can be used to treat anterior, posterior, and bileaflet prolapse at the commissure.

Commissural closure can be considered a modification or evolution of the so-called magic stitch, described by Carpentier. ${ }^{13}$ Unlike the "magic stitch," however, commissural closure consists of the complete suturing of the entire commissural area of prolapse. Suturing both leaflets together seems to challenge the fundamental surgical concepts of MV repair and raises a number of questions about the risk of inducing mitral stenosis, the degree of impairment of mitral leaflet motion, and the overall long-term durability. Moreover, the importance of the associated annuloplasty ring to support the commissural closure to improve the durability of the repair should be emphasized.

Certainly, commissural closure is a "functional," rather than an "anatomic," repair; however, according to our experience and our long-term results, it does not cause any significant restriction. This was confirmed by the low transvalvular pressure gradients recorded immediately after surgery and at the last echocardiographic follow-up examination and by the excellent clinical condition of the patients. The lack of stenosis was not surprising, given the pliability of leaflet tissue in patients with degenerative disease. Even patients treated with a central edge-to-edge repair have not developed significant restriction either at rest or during exercise. ${ }^{24}$ In addition, commissural closure provides a good area of leaflet coaptation, enhancing the apposition of the leaflets, particularly in the portion of the valve that is adjacent to the edge-to-edge suture. Finally, the excellent durability observed in our series seems to confirm that the supposed drawbacks and risks of this technique are more theoretical than practical.

As with any surgical technique, the only method to validate the commissural closure approach is using standard outcome measures and analysis. Our clinical and echocardiographic data have demonstrated excellent long-term results in terms of freedom from both MR and mitral stenosis up to 15 years postoperatively. Therefore, commissural closure remains the method of choice to correct isolated commissural prolapse at our institution. Because of its simplicity, reproducibility, and durability, commissural closure could hopefully increase the number of reconstructive procedures performed in patients with isolated commissural lesions.

\section{Study Limitations}

All the well-known limitations of every retrospective study also apply to the present series. Considering the study period, the number of patients included was relatively small. Despite that, our study remains one of the largest series of patients with MR due to commissural lesions treated with this technique. Although mitral stenosis at rest was never detected, exercise echocardiography to exclude this event under stress was not performed in this specific subgroup of patients. However, exercise echocardiographic data obtained in patients undergoing central edge-to-edge repair have demonstrated that mitral stenosis did not occur under stress, even for those patients with a double-orifice valve, in whom a more important reduction of the global MV area should be expected compared with that resulting from commissural closure. ${ }^{24}$ In addition, the optimal clinical condition of the patients, who were all in NYHA class I to II at follow-up, makes this possibility very unlikely. Nevertheless, additional studies regarding this issue are warranted.

\section{References}

1. Gillinov AM, Cosgrove DM, Blackstone EH, Diaz R, Arnold JH, Lytle BW, et al. Durability of mitral valve repair for degenerative disease. J Thorac Cardiovasc Surg. 1998;111:734-43.

2. Adams DH, Anyanwu AC, Rahmanian PB, Abascal V, Salzberg SP, Filsoufi F. Large annuloplasty rings facilitate mitral valve repair in Barlow's disease. Ann Thorac Surg. 2006;82:2096-100.

3. Gillinov AM, Blackstone EH, Nowicki ER, Slisatkorn W, Al-Dossari G, Johnston DR, et al. Valve repair versus valve replacement for degenerative mitral valve disease. J Thorac Cardiovasc Surg. 2008;135:885-93.

4. Braunberger E, Deloche A, Berrebi A, Abdallah F, Celestin JA, Meimoun P, et al. Very long-term results (more than 20 years) of valve repair with Carpentier's techniques in nonrheumatic mitral valve insufficiency. Circulation. 2001; 104(suppl I):I-8-11.

5. Zussa C, Frater RW, Polesel E, Galloni M, Valfré C. Artificial mitral valve chor dae: experimental and clinical experience. Ann Thorac Surg. 1990;50:367-73.

6. Mathieu P, Dagenais F, De Ibarra JIS, Baillot R. Surgical treatment of commissural prolapse: case report and review of the options. J Heart Valve Dis. 2004;13: $142-4$.

7. Aubert S, Barreda T, Acar C, Leprince P, Bonnet N, Ecochard R, et al. Mitral valve repair for commissural prolapse: surgical techniques and long term results. Eur J Cardiothorac Surg. 2005;28:443-7.

8. Van Herwerden LA, Taams MA, Bos E. Repair of commissural prolapse by extended leaflet sliding. Ann Thorac Surg. 1994;57:387-90.

9. Dreyfus G, Aubert S. Should mitral valve prolapse, even though commissural, be treated by suturing both leaflets together? Ann Thorac Surg. 2006;81:2339-40.

10. Zegdi R, Khabbaz Z, Flecher E, Latrémouille C, Noghin M, Chauvaud S, et al Management of commissural lesions in native mitral valve endocarditis: longterm results of valve repair and partial homograft replacement. J Heart Valve Dis. 2006;15:356-9.

11. El Khoury G, d'Udekem Y, Noirhomme P, Verhelst R, Rubay J, Dion R. Transfer of the posterior leaflet of the tricuspid valve to the mitral valve. J Heart Valve Dis. 2000;9:350-2.

12. Lapenna E, De Bonis M, Sorrentino F, La Canna G, Grimaldi A, Torracca L, et al Commissural closure for the treatment of commissural mitral valve prolapse or flail. J Heart Valve Dis. 2008;17:261-6.

13. Carpentier A. Cardiac valve surgery-the "French correction" J Thorac Cardiovasc Surg. 1983;86:323-37.

14. Stewart WJ, Currie PJ, Salcedo EE, Klein AL, Marwick T, Agler DA, et al. Evaluation of mitral leaflet motion by echocardiography and jet direction by Doppler color flow mapping to determine the mechanisms of mitral regurgitation. J Am Coll Cardiol. 1992;20:1353-6.

15. Heinle SK, Hall SA, Brickner ME, Willett DL, Grayburn PA. Comparison of vena contracta width by multiplane transesophageal echocardiography with quantitative Doppler assessment of mitral regurgitation. Am J Cardiol. 1998; 81:175-9.

16. Anderson RH, Zuberbuhler JR, Penkoske PA, Neches WH. Of clefts, commissures, and things. J Thorac Cardiovasc Surg. 1985;90:605-10.

17. Shimomura T, Toyama M, Takagi Y, Usui A, Ueda Y. Edge-to-edge technique to repair mitral commissural prolapse. Jpn J Thorac Cardiovasc Surg. 2006;54: 516-9.

18. Higuchi K, Koseni K, Inaba H, Osawa H, Kinoshita O, Takamoto S. Reinforced edge-to-edge commissural closure with mitral valvuloplasty. J Card Surg. 2007; 22:137-8

19. Gillinov AM, Shortt KG, Cosgorve DM III. Commissural closure for repair of mitral commissural prolapse. Ann Thorac Surg. 2005;80:1135-6. 
20. Duran CMG. Surgical techniques for the repair of anterior mitral leaflet prolapse. J Card Surg. 1999;14:471-81.

21. Alvarez JM, Deal CW, Loveridge K, Brennan P, Eisenberg R, Ward M, et al. Repairing the degenerative mitral valve: ten-to fifteen-year follow-up. $J$ Thorac Cardiovasc Surg. 1996;112:238-47.

22. Lai DTM, Chard RB. Commissuroplasty: a method of valve repair for mitral and tricuspid endocarditis. Ann Thorac Surg. 1999;68:1727-30.
23. Lessana A, Romano M, Lutfalla G, Carbone C, Palsky E, Amalou SA, et al. Treatment of ruptured or elongated anterior mitral valve chordae by partial transposition of the posterior leaflet: experience with 29 patients. Ann Thorac Surg. 1988;45:404-8

24. Agricola E, Maisano F, Oppizzi M, De Bonis M, Torracca L, La Canna G, et al. Mitral valve reserve in double-orifice technique: an exercise echocardiographic study. J Heart Valve Dis. 2002;11:637-43.

Access to The Journal of Thoracic and Cardiovascular Surgery Online is reserved for print subscribers!

Full-text access to The Journal of Thoracic and Cardiovascular Surgery Online is available for all print subscribers. To activate your individual online subscription, please visit The Journal of Thoracic and Cardiovascular Surgery Online, point your browser to http://www.mosby.com/jtcvs, follow the prompts to activate your online access, and follow the instructions. To activate your account, you will need your subscriber account number, which you can find on your mailing label (note: the number of digits in your subscriber account number varies from 6 to 10). See the example below in which the subscriber account number has been circled:

\section{Sample mailing label}

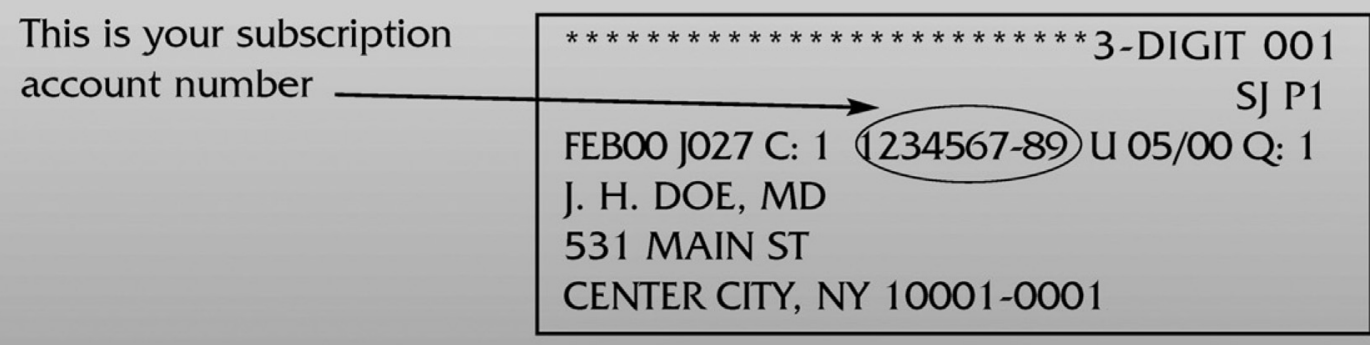

Personal subscriptions to The Journal of Thoracic and Cardiovascular Surgery Online are for individual use only and may not be transferred. Use of The Journal of Thoracic and Cardiovascular Surgery Online is subject to agreement to the terms and conditions as indicated online. 